\title{
Is there a need for dedicated devices?
}

\author{
Joanna J. Wykrzykowska ${ }^{1 *}$, MD, PhD; Maik J. Grundeken¹, MD; Goran Stankovic ${ }^{2}$, MD, PhD;
} Carlo Di Mario ${ }^{3}, \mathrm{MD}, \mathrm{PhD}$

1. Amsterdam Heartcenter, Academic Medical Center, University of Amsterdam, Amsterdam, The Netherlands; 2. Department of Cardiology, Clinical Center of Serbia, Medical Faculty, University of Belgrade, Belgrade, Serbia; 3. National Institute for Health Research (NIHR) Cardiovascular Biomedical Research Unit, Royal Brompton Hospital, Imperial College, London, United Kingdom

The complete references and the accompanying supplementary data are published online at: http://www:pcronline.com/eurointervention/V_issue/31

\begin{tabular}{l} 
KEYWORDS \\
\hline - Axxess \\
- bifurcation lesion \\
- BiOSS \\
- dedicated \\
bifurcation stent \\
- mother-daughter \\
stent platform \\
- Nile stent \\
- provisional strategy \\
- STENTYS \\
- Tryton Side Branch \\
Stent \\
- two-stent strategy \\
\end{tabular}

\section{Abstract}

Although the provisional approach is recommended over a systematic two-stent approach in bifurcation lesions, an a priori two-stent approach may be considered in certain specific anatomies in a minority of cases. Virtual bench test and intravascular imaging studies have provided essential insights into the technical aspects of bifurcation stenting and led to recommendations on how to optimise both the provisional and the two-stent strategies. Dedicated bifurcation stents may further optimise the procedural and clinical outcomes of both strategies. However, randomised data are sparse and more randomised trials are needed to provide evidence as to whether these dedicated devices will indeed improve procedural and clinical outcomes.

*Corresponding author: Department of Cardiology, B2-127, Academic Medical Center, Meibergdreef 9, 1105 AZ Amsterdam, The Netherlands. E-mail: j.j.wykrzykowska@amc.uva.nl 


\section{Introduction}

Bifurcation lesions are encountered by interventional cardiologists in daily clinical practice in approximately $15 \%-20 \%$ of their percutaneous coronary intervention (PCI) cases. Multiple randomised trials, comparing a routine two-stent strategy with a provisional strategy (i.e., single stent in the main branch with additional side branch stenting only if indicated) have shown comparable efficacy outcomes (target vessel/lesion revascularisation rates) between the two treatment strategies ${ }^{1-3}$. However, the same trials also showed that the provisional strategy resulted in lower rates of periprocedural myocardial infarction (MI), less contrast use, lower X-ray doses and shorter procedural times ${ }^{1-3}$. Based on these data, the European Bifurcation Club (EBC) recommends the provisional strategy as the default strategy in the vast majority of bifurcation lesions ${ }^{4}$. However, there is also a consensus that it is reasonable to consider an upfront strategy with two stents if a large side branch is involved, if there is extensive side branch disease, if side branch occlusion is likely and/or if rewiring is anticipated to be difficult ${ }^{4,5}$. However, it remains a challenge to distinguish these more complex bifurcation lesions which are likely to require complex stenting procedures with multiple stents from the more "simple" bifurcation lesions which are likely to be adequately treated with the provisional approach. The "DEFINITION" study recently proposed a definition to define complex bifurcation lesions. However, this DEFINITION "score" needs to be validated in other bifurcation databases ${ }^{6}$. Multiple dedicated bifurcation devices have been developed over the last decade, to facilitate both the provisional (single) stent strategy and a more complex multi-stent approach. Most companies developing such devices have discontinued their efforts due to disappointing results and difficulties in improving the already excellent outcomes of the current bifurcation treatment using conventional newer-generation DES. In this paper we will discuss the current challenges of PCI of bifurcation lesions and how bifurcation devices may potentially improve procedural and clinical outcomes.

\section{Why do we need dedicated devices to facilitate the provisional approach?}

Virtual bench tests and intravascular imaging studies have provided essential insights into how to improve the provisional strategy, including rewiring through a distal stent cell ${ }^{7-10}$, main branch stent sizing according to the distal main branch ${ }^{4,11}$, and the use of the proximal optimisation technique (POT) ${ }^{12}$. However, challenges remain when using the provisional strategy. These include difficulties with side branch rewiring, proper stent sizing when there are large diameter differences between the proximal and distal main branch, and difficulties in performing final kissing balloon dilatation. Dedicated bifurcation stents may be helpful in overcoming these remaining challenges, further improving the provisional approach.

\section{How dedicated stents potentially improve the provisional stenting strategy DIFFICULTIES WITH REWIRING}

Rewiring the side branch after main branch stent placement can sometimes be technically challenging and time-consuming.
The Nile ${ }^{\circledR}$ stent (Minvasys, Gennevilliers, France) (Figure 1A) and the mother-daughter stent platforms (Advanced Bifurcation Systems [ABS], Los Angeles, CA, USA) may overcome this problem since both stents are advanced over two wires with access to both branches throughout the complete procedure. However, advancement over two wires may in its own right give rise to other technical problems such as wire twist, necessitating re-crossing ${ }^{13,14}$. These devices also tend to be more bulky and have worse crossing profiles than conventional stents. Another solution for difficulty in rewiring is provided by the $\mathrm{BiOSS}^{\circledR}$ dedicated bifurcation stent (Balton, Warsaw, Poland). This stent consists of proximal and distal stent parts, which are connected by only two connecting struts (Figure 1B). When the stent is positioned, it automatically "opens" itself towards the side branch because of its bending, especially when the proximal-to-distal main branch angle is relatively narrow ${ }^{15}$. This might theoretically simplify the rewiring into the side branch ${ }^{16}$. The conically shaped selfexpanding nitinol Axxess ${ }^{\mathrm{TM}}$ stent (Biosensors Europe SA, Morges, Switzerland), which is placed in the proximal main branch up to the carina over a single wire, has a big advantage in that it does not cross one of the distal branches, leaving both daughter vessels freely accessible after placement (Figure 2) ${ }^{17-20}$.

\section{DIFFICULTIES IN SIZING APPROPRIATELY}

Due to the fractal geometry of the coronary tree, proximal and distal diameters are per definition different ${ }^{21,22}$. Although sizing according to the distal diameter with additional POT did provide a solution to prevent carina shift while ensuring adequate proximal stent expansion and apposition when using conventional stents, it might be difficult to achieve optimal results when there is a large difference between the proximal and distal diameters. For this reason, the BiOSS stent is mounted on a stepped balloon with a larger proximal diameter than the distal part (in a ratio of 1.15-1.30) ${ }^{23}$. The STENTYS stent (STENTYS S.A., Paris, France) proposes a different
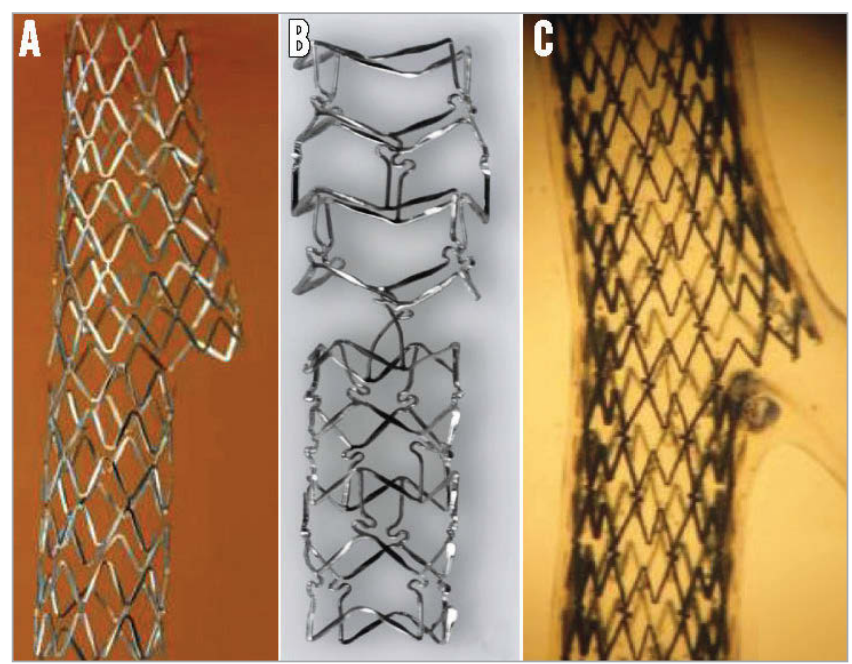

Figure 1. Currently available dedicated bifurcation stents facilitating a provisional approach (according to " $A$ " [main across side branch] of the MADS classification). A) The Nile stent. B) The BiOSS stent. C) The STENTYS stent. 


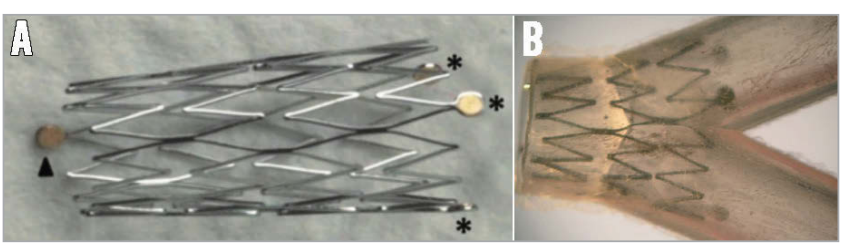

Figure 2. The conically shaped self-expanding nitinol Axxess stent. A) An expanded Axxess stent. The three asterisks indicate the three distal markers, while the arrowhead indicates the single proximal marker. B) Placement of an Axxess stent in a silicone model. Adapted with permission from Dubois and Wijns ${ }^{17}$.

solution to the problem (Figure 1C). The nitinol stent is deployed by retracting a sheath constraining the stent after which it expands itself until it reaches the vessel wall. The self-expanding stent adapts its calibre to the calibre of the distal and proximal vessel. The properties of the stent allow it to expand further beyond its indicated vessel diameters: the "medium-sized" STENTYS, for instance, suitable for vessels with diameters of 3.0-3.5 mm, expands up to $5.3 \mathrm{~mm}$. The self-expanding Axxess stent has the obvious advantage that stent sizing can be performed for each bifurcation segment (i.e., proximal main, distal main and side branch) separately, with the additional advantage that the device fits the natural anatomy of the polygon of confluence of the bifurcation core (Figure 2) ${ }^{20}$.

\section{DIFFICULTIES WITH FINAL KISSING BALLOON DILATATION}

Side branch rewiring, needed to perform final kissing balloon dilatation, can be technically challenging and is not always possible. Furthermore, final kissing balloon dilatation itself might result in less favourable results in the proximal main branch, including stent strut malapposition and oval-shaped stent distortion when left uncorrected. A dedicated stent which does not deform during final kissing dilatation or does not need final kissing dilatation might not only simplify the procedure, but may also result in favourable outcomes. An example of such a device is the STENTYS stent. By disconnecting the interconnectors (i.e., the struts connecting subsequent hoops) using side branch dilatation, the stent part proximal to this disconnection flares open into the side branch ostium, while the stent distortions in the main branch which are usually seen after side branch dilatation are automatically corrected due to the memory shape of the stent. For the BiOSS stent, the stent cell opening in the connecting middle part might already provide a sufficient opening towards the side branch ostium without overhanging struts such that final kissing might be less essential in this device. When no additional stents are placed in the daughter vessels, the Axxess stent probably does not require final kissing balloon dilatation either.

\section{Treatment of Medina 0,0,1 lesions}

A real remaining challenge in bifurcation treatment is how properly to treat bifurcation lesions in which only the side branch ostium is involved (Medina 0,0,1). When performing ostial stenting, there is the potential risk of leaving a gap at the ostium if the stent is placed too distally, and there is also the risk of protruding stent struts if the stent is placed too proximally. In theory, adequate ostial coverage without protruding struts can only be achieved when the distal bifurcation angle is 90 degrees. Therefore, Brunel et al proposed the “inverted provisional T stenting", placing a conventional DES from the side branch to the proximal main branch, leaving a large amount of metal in the non-diseased proximal main branch ${ }^{24}$. Although none of the current bifurcation devices has been specifically designed to treat Medina 0,0,1 bifurcation lesions, it has been proposed to treat these lesions using the Tryton stent (Tryton Medical, Inc., Durham, NC, USA) without an additional main branch stent (as in the Brunel technique, but then leaving only a minimal amount of metal). This has shown encouraging results in 12 patients ${ }^{25}$.

\section{Why do we need dedicated devices to facilitate a two-stent approach?}

Although no-one knows exactly in what percentage of patients with bifurcation lesions an a priori two-stent approach is the appropriate treatment, it is likely only to be a small minority. So, per definition, it will be a challenge to gain enough experience to master one or more of these complex two-stent techniques. Furthermore, all two-stent techniques have some drawbacks caused by the limitations of conventional stents, such as a limited expansion caused by the cell size through which the second stent is crossed in culotte, or the three layers of struts when using crush. Therefore, there is an unmet need for a dedicated stent which simplifies the two-stent approach. This stent should ideally fulfil the following criteria: the device should have a short learning curve, it should simplify the procedure (i.e., shorter procedural times, less contrast use), should adjust to the wide variety of bifurcation anatomies (including a wide range of distal bifurcation angles), should improve procedural success rates, should have a predictable acute result in the side branch, and should ensure longterm patency of the side branch without jeopardising the acute and long-term results in the main branch. Although a true "bifurcated" (Y-shaped) stent has always been "every interventionalist's dream"26 because of its potential to solve all problems at once (Figure 3), such devices have turned out to be very bulky and, because they had to be advanced over two wires, there was a chance of wire wrap and misalignment. Such stents are currently no longer under development ${ }^{27-31}$.

\section{How dedicated stents potentially improve a two-stent strategy}

To the best of our knowledge, only two bifurcation stents facilitating the two-stent approach are currently under clinical investigation: the Tryton Side Branch Stent ${ }^{\mathrm{TM}}$ (Tryton Medical, Inc.) and the mother-daughter stent platform (Advanced Bifurcation Systems [ABS], Los Angeles, CA, USA).

The mother-daughter stent platform (currently only available in a bare metal version) consists of a mother stent (deployed in the main branch) and a daughter stent (deployed in the side branch), and could be considered as a systematic T-stent strategy (Figure 3 ). This device, advanced over two wires, is unique because the side branch stent deployment is performed simultaneously with the deployment of the proximal part of the main branch stent ${ }^{14}$. In theory, this will 


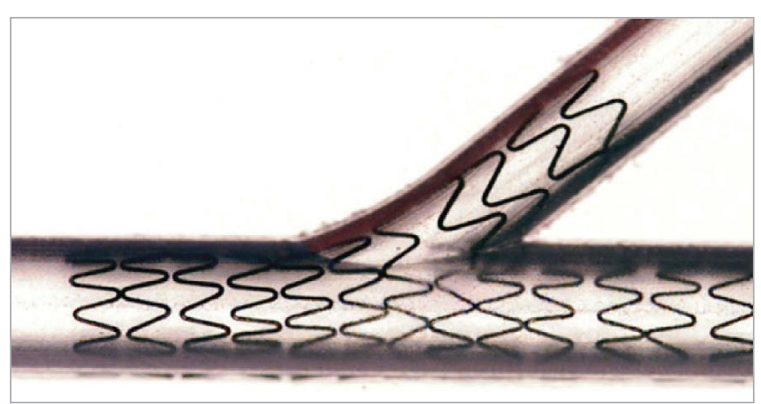

Figure 3. The Medtronic Y-shaped bifurcation-dedicated stent (BDS) (Medtronic Inc., Santa Rosa, CA, USA). Although it is "every interventionalist's dream" to have one device to solve all problems at once and to treat the entire bifurcation, such devices are no longer under development. From Lefèvre et al ${ }^{26}$ with permission.

lead to better alignment of the side branch stent at the ostium without leaving a gap between both stents ${ }^{9}$. However, clinical experience is very limited, and more studies are needed ${ }^{14}$. The Tryton stent (currently available in bare metal only) facilitates an inverse culotte technique (according to the MADS classification ${ }^{32}$ ), in which the side branch is treated first (Online Figure 1) ${ }^{33,34}$. The stent is available mounted on a stepped balloon with different proximal and distal diameters, obeying the fractal geometry of the coronary tree $\mathrm{e}^{21,22,34}$. Furthermore, the special design of the stent with a minimal amount of metal with large stent cells in the (proximal) main branch zone allows easy delivery of a DES in the main branch without restricting the stent expansion to a certain limit, as seen with the culotte technique (the so-called "napkin-ring effect") ${ }^{35,36}$.

The use of the Tryton has been shown to be feasible with a delivery success rate of around $96 \% 0^{37-39}$. The Tryton IDE trial showed that the use of the Tryton resulted in a predictable result at the side branch in terms of post-procedure in-segment percentage diameter stenosis (Tryton $11.98 \pm 9.64 \%$ vs. provisional $30.51 \pm 17.19 \%$, $\mathrm{p}<0.001)^{39}$. However, the primary clinical non-inferiority endpoint of the Tryton IDE trial was not met due to a numerically higher rate of periprocedural myocardial infarction (MI). This difference in periprocedural MI might be explained by the inclusion of relatively small side branches in the trial (approximately $60 \%$ did not meet the inclusion criterion of side branch diameter $<2.5 \mathrm{~mm}$ ). Future studies are needed to confirm that there is no increased risk of periprocedural MI when using this device in sufficiently sized side branches (i.e., $>2.5 \mathrm{~mm}$ ) and to assess whether the device needs a drug coating to improve its efficacy.

\section{Combined use of dedicated bifurcation stents with bioresorbable scaffolds}

The use of a bioresorbable scaffold (BRS) as the main branch stent in provisional bifurcation treatment might result in favourable longterm results, especially at the side branch ostium. The mechanism of this potential benefit could be due to the resorption of the jailed side branch struts. The hypothesis is that this would in turn eliminate the potential trigger for late stent thrombosis (ST) and prevent late side branch restenosis caused by the jailed non-apposed side branch struts, as occurs with metallic stents.

However, when a two-stent approach is deemed necessary it has been reported that the currently available BRS could be prone to strut fracture when the scaffold is dilated with an oversized balloon (during fenestration and/or with the POT technique) or when final kissing balloon dilatation is performed using balloons at high pressure $^{40}$. Our group has tested one of the "hybrid" approaches, combining the Absorb BVS (Abbott Vascular, Santa Rosa, CA, USA) in the main branch with the Tryton dedicated bifurcation stent as side branch treatment. However, the initial results were not favourable enough to recommend this approach being used on a large scale in daily clinical practice ${ }^{41}$.

\section{Future perspectives}

The Tryton IDE trial has made it clear how difficult it is to select appropriately the bifurcation lesions which fulfil the predefined inclusion criteria. Since visual estimation has proved to be inaccurate, future bifurcation trials may base patient eligibility on a core lab QCA analysis confirmation of the angiographic inclusion criteria (or, even better, intravascular ultrasound). Furthermore, more studies such as DEFINITION are needed to evaluate further which bifurcation lesions are "complex" and may benefit from a twostent approach. Dedicated devices facilitating a two-stent strategy should be compared with a two-stent approach using contemporary DES in these complex bifurcation lesions, whereas dedicated stents facilitating the provisional strategy should be compared with a provisional approach using contemporary DES in the remaining. It is conceivable that dedicated devices can only compete with contemporary, tubular DES if they are at least comparable in terms of strut thickness, polymer biocompatibility, and drug efficacy, so that the specific stent design provides an advantage which will improve procedural and clinical outcomes.

\section{Conclusions}

Dedicated bifurcation stents may be helpful to simplify the procedure and to improve clinical outcomes further after both the provisional approach and the two-stent approach to treat bifurcation lesions. More randomised trials comparing these devices with contemporary DES are needed to evaluate their potential benefit in daily clinical practice.

\section{Conflict of interest statement}

J. Wykrzykowska has received speaker and/or consultancy fees from Abbott, St. Jude, Tryton Medical, and STENTYS. The other authors have no conflicts of interest to declare.

\section{References}

The references can be found in the online version of the paper.

\section{Online data supplement}

Online Figure 1. Two dedicated bifurcation devices which facilitate the two-stent approach. 


\section{Online data supplement}

\section{References}

1. Steigen TK, Maeng M, Wiseth R, Erglis A, Kumsars I, Narbute I, Gunnes P, Mannsverk J, Meyerdierks O, Rotevatn S, Niemela M, Kervinen K, Jensen JS, Galloe A, Nikus K, Vikman S, Ravkilde J, James S, Aaroe J, Ylitalo A, Helqvist S, Sjogren I, Thayssen P, Virtanen K, Puhakka M, Airaksinen J, Lassen JF, Thuesen L; Nordic PCI Study Group. Randomized study on simple versus complex stenting of coronary artery bifurcation lesions: the Nordic bifurcation study. Circulation. 2006;114:1955-61.

2. Colombo A, Bramucci E, Sacca S, Violini R, Lettieri C, Zanini R, Sheiban I, Paloscia L, Grube E, Schofer J, Bolognese L, Orlandi M, Niccoli G, Latib A, Airoldi F. Randomized study of the crush technique versus provisional side-branch stenting in true coronary bifurcations: the CACTUS (Coronary Bifurcations: Application of the Crushing Technique Using Sirolimus-Eluting Stents) Study. Circulation. 2009;119:71-8.

3. Hildick-Smith D, de Belder AJ, Cooter N, Curzen NP, Clayton TC, Oldroyd KG, Bennett L, Holmberg S, Cotton JM, Glennon PE, Thomas MR, Maccarthy PA, Baumbach A, Mulvihill NT, Henderson RA, Redwood SR, Starkey IR, Stables RH. Randomized trial of simple versus complex drug-eluting stenting for bifurcation lesions: the British Bifurcation Coronary Study: old, new, and evolving strategies. Circulation. 2010;121:1235-43.

4. Lassen JF, Holm NR, Stankovic G, Lefèvre T, Chieffo A, Hildick-Smith D, Pan M, Darremont O, Albiero R, Ferenc M, Louvard Y. Percutaneous coronary intervention for coronary bifurcation disease: consensus from the first 10 years of the European Bifurcation Club meetings. EuroIntervention. 2014;10:545-60.

5. Levine GN, Bates ER, Blankenship JC, Bailey SR, Bittl JA, Cercek B, Chambers CE, Ellis SG, Guyton RA, Hollenberg SM, Khot UN, Lange RA, Mauri L, Mehran R, Moussa ID, Mukherjee D, Nallamothu BK, Ting HH; American College of Cardiology Foundation; American Heart Association Task Force on Practice Guidelines; Society for Cardiovascular Angiography and Interventions. $2011 \mathrm{ACCF} / \mathrm{AHA} / \mathrm{SCAI}$ Guideline for Percutaneous Coronary Intervention. A report of the American College of Cardiology Foundation/American Heart Association Task Force on Practice Guidelines and the Society for Cardiovascular Angiography and Interventions. J Am Coll Cardiol. 2011;58:e44-122.

6. Chen SL, Sheiban I, Xu B, Jepson N, Paiboon C, Zhang JJ, Ye F, Sansoto T, Kwan TW, Lee M, Han YL, Lv SZ, Wen SY, Zhang Q, Wang HC, Jiang TM, Wang Y, Chen LL, Tian NL, Cao F, Qiu CG, Zhang YJ, Leon MB. Impact of the complexity of bifurcation lesions treated with drug-eluting stents: the DEFINITION study (Definitions and impact of complEx biFurcation lesIons on clinical outcomes after percutaNeous coronary IntervenTIOn using drug-eluting steNts). JACC Cardiovasc Interv. 2014;7:1266-76.

7. Foin N, Torii R, Alegria E, Sen S, Petraco R, Nijjer S, Ghione M, Davies JE, Di Mario C. Location of side branch access critically affects results in bifurcation stenting: Insights from bench modeling and computational flow simulation. Int $J$ Cardiol. 2013;168:3623-8.

8. Alegria-Barrero E, Foin N, Chan PH, Syrseloudis D, Lindsay AC, Dimopolous K, Alonso-Gonzalez R, Viceconte N, De Silva R, Di Mario C. Optical coherence tomography for guidance of distal cell recrossing in bifurcation stenting: choosing the right cell matters. EuroIntervention. 2012;8:205-13.

9. Ormiston JA, Webster MW, El Jack S, Ruygrok PN, Stewart JT, ScottD, Currie E, Panther MJ, Shaw B, O'Shaughnessy B. Drug-eluting stents for coronary bifurcations: bench testing of provisional side-branch strategies. Catheter Cardiovasc Interv. 2006;67: 49-55.

10. Okamura T, Onuma Y, Yamada J, Iqbal J, Tateishi H, Nao T, Oda T, Maeda T, Nakamura T, Miura T, Yano M, Serruys PW. 3D optical coherence tomography: new insights into the process of optimal rewiring of side branches during bifurcational stenting. EuroIntervention. 2014;10:907-15.

11. Kang SJ, Mintz GS, Kim WJ, Lee JY, Oh JH, Park DW, Lee SW, Kim YH, Lee CW, Park SW, Park SJ. Changes in left main bifurcation geometry after a single-stent crossover technique: an intravascular ultrasound study using direct imaging of both the left anterior descending and the left circumflex coronary arteries before and after intervention. Circ Cardiovasc Interv. 2011;4:355-61.

12. Foin N, Secco GG, Ghilencea L, Krams R, Di Mario C. Final proximal post-dilatation is necessary after kissing balloon in bifurcation stenting. EuroIntervention. 2011;7:597-604.

13. Berland J. The Nile CroCo and Nile PAX stents. EuroIntervention. 2015;11 Suppl V:V149-50.

14. Khorsandi M, Abizaid A, Dani S, Bourang H, Costa R, Kar S, Makkar RR. Advanced Bifurcation Systems mother-daughter platform. EuroIntervention. 2015;11 Suppl V:V151-2.

15. Grundeken MJ, Magro, M, Gil R, Briguori C, Sardella G, Berland J, Wykrzykowska JJ, Serruys PW. Dedicated stents for distal left main stenting. EuroIntervention. 2015;11 Suppl V:V129-34.

16. Foin N, Sen S, Allegria E, Petraco R, Nijjer S, Francis DP, Di Mario C, Davies JE. Maximal expansion capacity with current DES platforms: a critical factor for stent selection in the treatment of left main bifurcations? EuroIntervention. 2013;8:1315-25.

17. Dubois CL, Wijns W. The AXXESS self-expanding biolimus A9 eluting stent system for coronary bifurcation lesions. EuroIntervention. 2010;6 Suppl J:J130-4.

18. Buysschaert I, Verheye S. The Axxess stent. EuroIntervention. 2015;11 Suppl V:V143-4.

19. Buysschaert I, Dubois CL, Dens J, Ormiston J, Worthley S, McClean D, Ottervanger JP, Meredith I, Uren N, Wijns W, Whitbourn R, Mehran R, Lansky AJ, Bichalska M, Meis S, Verheye S. Three-year clinical results of the Axxess Biolimus A9 eluting bifurcation stent system: the DIVERGE study. EuroIntervention. 2013;9:573-81. 
20. Dubois C, Bennett J, Dens J, De Cock D, Desmet W, Belmans A, Ughi J, Sinnaeve P, Vrolix M, D'hooge J, Adriaenssens T. COmplex Coronary Bifurcation Lesions: RAndomized Comparison of a Strategy using a Dedicated Self-Expanding Biolimus-eluting Stent versus a Culotte Strategy using Everolimus-eluting Stents: primary results of the COBRA trial. EuroIntervention. 2015 May [Epub ahead of print].

21. Huo Y, Kassab GS. A scaling law of vascular volume. Biophys J. 2009;96:347-53.

22. Huo Y, Finet G, Lefèvre T, Louvard Y, Moussa I, Kassab GS. Optimal diameter of diseased bifurcation segment: a practical rule for percutaneous coronary intervention. EuroIntervention. 2012;7: 1310-6.

23. Gil RJ, Bil J, Vassilev D. The BiOSS stent. EuroIntervention. 2015;11 Suppl V:V153-4.

24. Brunel P, Martin G, Bressollette E, Leurent B, Banus Y. "Inverted" provisional T stenting, a new technique for Medina 0,0,1 coronary bifurcation lesions: feasibility and follow-up. EuroIntervention. 2010;5:814-20.

25. Grundeken MJ, Agostoni P, Lesiak M, Koch KT, Voskuil M, de Winter RJ, Wykrzykowska JJ, Stella PR. Placement of Tryton Side Branch Stent only; a new treatment strategy for Medina 0,0,1 coronary bifurcation lesions. Catheter Cardiovasc Interv. 2013; 82:E395-402.

26. Lefèvre T, Chevalier B, Louvard Y. Is there a need for dedicated bifurcation devices? EuroIntervention. 2010;6 Suppl J:J123-9.

27. Colombo A, Airoldi F, Sheiban I, Di Mario C. Successful treatment of a bifurcation lesion with the Carina Bard stent: A case report. Catheter Cardiovasc Interv. 1999;48:89-92.

28. Carlier SG, van der Giessen WJ, Foley DP, Kutryk MJ, Rensing BJ, Carleton ML, Serruys PW. Stenting with a true bifurcated stent: acute and mid-term follow-up results. Catheter Cardiovasc Interv. 1999;47:361-96.

29. Toutouzas K, Stankovic G, Takagi T, Albiero R, Corvaja N, Milici C, Di Mario C, Finci L, Colombo A. A new dedicated stent and delivery system for the treatment of bifurcation lesions: preliminary experience. Catheter Cardiovasc Interv. 2003;58:34-42.

30. Abizaid A, de Ribamar Costa J Jr, Alfaro VJ, Feres F, Staico R, Mattos LA, Maldonado G, Sousa JE. Bifurcated stents: giving to Caesar what is Caesar's. EuroIntervention. 2007;2: 518-25.

31. Dibie A, Chevalier B, Guyon P, Fajadet J, Lefèvre T, Slama MS, Royer T, Glatt B, Philippe F, Laborde F, Larrazet F. First-in-human feasibility and safety study of a true bifurcated stent for the treatment of bifurcation coronary artery lesions (DBS stent): six month angiographic results and five year clinical follow-up. EuroIntervention. 2008;3:558-65.

32. Louvard Y, Medina A, Stankovic G. Definition and classification of bifurcation lesions and treatments. EuroIntervention. 2010;6 Suppl J:J31-5.
33. Grundeken MJ, Généreux P, Wykrzykowska JJ, Leon MB, Serruys PW. The Tryton Side Branch Stent. EuroIntervention. 2015;11 Suppl V:V145-6.

34. Grundeken MJ, Stella PR, Wykrzykowska JJ. The Tryton Side Branch Stent for the treatment of coronary bifurcation lesions. Expert Rev Med Devices. 2013;10:707-16.

35. Murasato Y, Hikichi Y, Horiuchi M. Examination of stent deformation and gap formation after complex stenting of left main coronary artery bifurcations using microfocus computed tomography. J Interv Cardiol. 2009;22:135-44.

36. Hikichi Y, Inoue T, Node K. Benefits and limitations of cypher stent-based bifurcation approaches: in vitro evaluation using micro-focus CT scan. J Interv Cardiol. 2009;22:128-34.

37. Grundeken MJ, Asgedom S, Damman P, Lesiak M, Norell MS, Garcia E, Bethencourt A, Woudstra P, Koch KT, Vis MM, Henriques JP, Onuma Y, Foley DP, Bartorelli AL, Stella PR, Tijssen JG, de Winter RJ, Wykrzykowska JJ. Six-month and one-year clinical outcomes after placement of a dedicated coronary bifurcation stent: a patient-level pooled analysis of eight registry studies. EuroIntervention. 2013;9:195-203.

38. Tarantini G, La Vecchia L, Galli M, Favero L, D’Amico G, Buja P, Russo F, Cabianca E, Napodano M, Musumeci G, Franceschini E, Grassi G, Pavei A, Bonmassari R, Cernetti C, Spedicato L, Caprioglio F, Reimers B, Isabella G. Clinical outcome of patients with de novo coronary bifurcation lesions treated with the Tryton Side Branch Stent. The SAFE-TRY prospective multicenter single arm study. Int J Cardiol. 2013;168:5323-8.

39. Généreux P, Kumsars I, Lesiak M, Kini A, Fontos G, Slagboom T, Ungi I, Metzger C, Wykrzykowska JJ, Stella PR, Bartorelli AL, Fearon WF, Lefèvre T, Feldman RL, LaSalle L, Francese DP, Onuma Y, Grundeken MJ, Garcia-Garcia HM, Laak LL, Cutlip DE, Kaplan AV, Serruys PW, Leon MB. A randomized trial of a dedicated bifurcation stent versus provisional stenting in the treatment of coronary bifurcation lesions. $J$ Am Coll Cardiol. 2015;65:533-43.

40. Ormiston JA, Webber B, Ubod B, Webster MW, White J. Absorb everolimus-eluting bioresorbable scaffolds in coronary bifurcations: a bench study of deployment, side branch dilatation and post-dilatation strategies. EuroIntervention. 2015;10:1169-77.

41. Grundeken MJ, Hassell ME, Kraak RP, de Bruin DM, Koch KT, Henriques JP, van Leeuwen TG, Tijssen JG, Piek JJ, de Winter RJ, Wykrzykowska JJ. Treatment of coronary bifurcation lesions with the Absorb bioresorbable vascular scaffold in combination with the Tryton dedicated coronary bifurcation stent: evaluation using two- and three-dimensional optical coherence tomography. EuroIntervention. 2014 Aug 30. [Epub ahead of print]. 

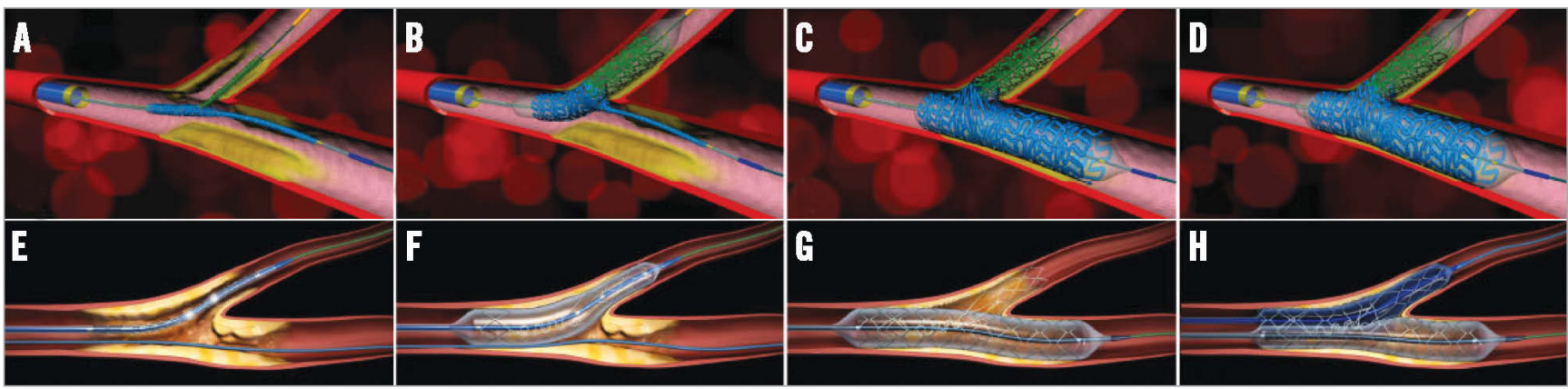

Online Figure 1. Two dedicated bifurcation devices which facilitate the two-stent approach: the mother-daughter stent platform (Advanced Bifurcation Systems [ABS], Los Angeles, CA, USA) (A-D) and the Tryton Side Branch Stent ${ }^{\mathrm{TM}}$ (Tryton Medical, Inc., Durham, NC, USA) (E-H). A) Positioning of the mother-daughter stent platform with proximal alignment of the daughter balloon catheter with the mother balloon catheter. B) Inflation of the daughter catheter. Note that not only the daughter stent is deployed, but also the proximal part of the mother stent is deployed by the proximal part of the daughter balloon catheter. This will, in theory, prevent the occurrence of gap formation at the side branch ostium, which often occurs when conventional stents are used. C) Subsequent deployment of the mother stent by inflating the mother balloon. D) Final kissing balloon dilation by inflating both mother and daughter balloons simultaneously, without the need for rewiring or advancing additional balloons. E) Positioning of the Tryton stent, after wiring both branches, by using the two middle markers on the delivery system. F) Inflation of the Tryton stent (note the stepped delivery balloon). G) Deployment of a conventional main branch stent (after POT, after wiring of the distal main branch and after removal of the "trapped"' main branch wire). H) After side branch rewiring, final kissing balloon inflation. 